\title{
A (IM) POSSIBILIDADE DO PATENTEAMENTO DO JAMBU AMAZÔNICO
}

\section{A (IM) POSSIBILITY OF THE AMAZON JAMBU PATENT}

\section{VALMIR CÉSAR POZZETTI}

Pós Doutor em direito à Alimentação Sadia, pela Universidade de Salerno/ltália; Doutor em Biodireito/Direito Ambiental pela Université de Limoges/França. Mestre em Direito do Urbanismo e do Meio Ambiente, pela Université de Limoges, França. Professor Adjunto da UFAM - Univ. Federal do Amazonas e da UEA - Univ. do Estado do Amazonas . E-mail: $\underline{v}$ pozzetti@hotmail.com

\section{MARIE JOAN NASCIMENTO FERREIRA}

Doutoranda em Ciências do Ambiente e Sustentabilidade na Amazônia pela Universidade Federal do Amazonas.Mestre em direito Ambiental pela UEA - Univ. do Estado do Amazonas. E-mail: marie-joan@hotmail.com

\section{MÁRYKA LUCY DA SILVA MENDES}

Discente Especial do Programa de Mestrado em Ciências Ambientais e Sustentabilidade na Amazônia, da UFAM - Universidade Federal do Amazonas. Email: maryka.mendes12@gmail.com

\section{RESUMO}

Objetivo: O objetivo desta pesquisa é analisar as recentes notícias veiculadas na mídia sobre o patenteamento de uma planta da região amazônica denominada jambu, e verificar se, à luz do ordenamento jurídico Pátrio, é possível patentear um organismo vegetal vivo sem qualquer alteração genética de melhoramento. 
Metodologia: A metodologia utilizada nessa pesquisa foi a do método dedutivo; quanto aos meios, a pesquisa foi a bibliográfica, com uso de doutrina, legislação e jurisprudência nacional e internacional; quanto aos fins, a pesquisa foi qualitativa.

Resultados: A conclusão a que se chegou foi a de que o ordenamento jurídico Pátrio não permite o patenteamento de qualquer ser vivo, sem que haja um melhoramento genético de suas qualidades e que, no caso do jambu, patenteá-lo não é possível.

Contribuições: A contribuição do presente trabalho é reconhecer a importância da Amazônia e de sua biodiversidade. A partir daí, chamar a atenção dos brasileiros, pesquisadores ou não, para a sua preservação não somente relativamente ao meio ambiente, como também pela riqueza da sua biodiversidade, que atrai interesses externos aos bens ambientais nela existentes. Esta temática perpassa pela análise das patentes, tangenciando pelo exemplo da planta denominada cupuaçu, patenteada por uma empresa japonesa, revertida a situação posteriormente junto a Organização Mundial do Comércio - OMC. Diante daquela experiência, o artigo contribui para a pesquisa científica, visando responder a problemática central: de que forma o Brasil pode evitar que povos alienígenas patenteiem plantas da biodiversidade amazônica? Neste particular, analisa-se o jambu. Este tema contribui para a pesquisa despertando a atenção dos brasileiros para algo que já foi há muito notado pelos povos alienígenas.

Palavras-chave: Biodiversidade; biopirataria; jambu; patente.

\section{ABSTRACT}

Objective: The objective of this research is to analyze the recent news published in the media about the patenting of a plant from the Amazon region called jambu and to verify whether, in the light of the Brazilian legal system it is possible to patent a living plant organism without any genetic improvement.

Methodology: The methodology used in this research is the deductive method; as for the means, the research was bibliographic, using national and international doctrine, legislation and jurisprudence; as for the purposes, the research was qualitative.

Results: The conclusion reached is that the Brazilian legal system does not allow the patenting of any living being without a genetic improvement of its qualities; in the case of jambu, it is not possible to patent it.

Contributions: The contribution of this paper is to recognize the importance of the Amazon and its biodiversity and call the attention of Brazilians, researchers or not, for its preservation not only in relation to the environment but also for the richness of its biodiversity, which attracts external interests to the environmental goods that exist in it. This theme runs through the analysis of patents, following the example of the plant 
called cupuaçu, patented by a Japanese company, which reversed the situation later with the World Trade Organization - WTO. In view of that experience, the article contributes to scientific research, aiming to answer the central question: how can Brazil prevent alien people from patenting plants of Amazonian biodiversity? In this regard, the jambu is analyzed. This theme contributes to the research, drawing the attention of Brazilians to something that has long been noticed by alien people.

Keywords: Biodiversity; biopiracy; jambu; patent.

\section{INTRODUÇÃO}

A floresta amazônica é uma floresta de mata fechada, com áreas submersas e com uma grande riqueza de fauna e flora, jamais encontrada em outras florestas do planeta. Nesse sentido a sua grandeza e biodiversidade, atrai cobiças de toda a ordem, o que a faz ser alvo frequente de "biopiratas", que se interessam em usurpar, gratuitamente, a vasta biodiversidade existente somente nessa parte do planeta.

Por volta de 1850, com a descoberta da árvore da seringueira, a Amazônia brasileira produziu matéria prima que subsidiou a elaboração de muitos equipamentos para a guerra e, com isso, iniciou-se os primeiros episódios de extração e exportação de recursos biológicos para serem manipulados e comercializados em outros países. À extração ilegal das sementes da seringa, deu-se o nome de biopirataria.

Dessa forma, tivemos o mesmo processo com o "pau rosa", cujo óleo, descobriu-se, era um poderoso fixador de aromas. Assim, também essa matéria prima foi utilizada pelas grandes empresas de perfumaria para fixar as fragrâncias por mais tempo à pelo. Tal produto também foi utilizado pelos europeus, sem pagar quaisquer royalties aos povos amazônidas.

Ainda hoje isso ocorre, ao longo do tempo, pois nem só os organismos vivos estão sendo retirados da natureza, mas também o conhecimento dos povos tradicionais, que economizaram décadas de investimentos em pesquisas, gerando um lucro maior sobre os produtos amazônicos, desenvolvido pelos biopiratas, resultando em perda econômica para o Brasil e para a região amazônica. 
Uma das plantas mais cobiçadas atualmente, pelos pesquisadores e empresas, é o JAMBU. A planta nativa da Amazônia, que possui propriedade anestésica, com grande valor medicinal, além disso, é muito utilizado na culinária regional, é considerada uma iguaria tanto para a alimentação, como para a medicação.

No início de 2018, foram veiculadas nos diversos veículos de comunicação, notícias de que essa planta foi patenteada pelo EUA - Estados Unidos da América e, assim, não sendo mais possível o desenvolvimento de pesquisas e produção de produtos a partir dela.

Tal notícia gerou grande alarde na comunidade científica local e na população em geral. Já não é a primeira vez que ocorre tamanho infortúnio com a flora da biodiversidade amazônica; pois outro exemplo, foi o patenteamento da planta "cupuaçu", feita por uma empresa Japonesa. Patentear significa o direito de receber royalties de quem usa o nome ou o produto. Mas o Brasil reagiu a essa incongruência japonesa e conseguiu reverter o quadro junto a OMS - Organização mundial do comércio.

Neste sentido, o objetivo dessa pesquisa é o de analisar a lei de patentes que vigora no Brasil e as singularidades quanto a possibilidade de patenteamento de organismos advindos da natureza.

A problemática que anima essa pesquisa é: de que forma o Brasil pode evitar que povos alienígenas patenteiem plantas da biodiversidade amazônica?

A pesquisa se justifica porque são inúmeras as investidas das empresas de alimentação, medicamentos e de cosméticos, que avançam o território amazônico numa tentativa de usurpar conhecimentos tradicionais e matéria prima, sem querer conceder ao país os retornos financeiros que lhe são de direito.

A metodologia a ser utilizada nessa pesquisa é a do método dedutivo, de onde se partirá das análises do que foi construído pela mídia, pelo legislador, e pela jurisprudência, para se chegar a uma dedução lógica. Quanto aos meios a pesquisa será a bibliográfica, com o auxílio da doutrina, sites de notícias na internet, legislação 
e jurisprudência; quanto aos fins a pesquisa será qualitativa, pois se pretende trazer como resultado uma conclusão que norteará as inquietações da sociedade.

\title{
2 AS NOTÍCIAS E SUAS REPERCUSSÕES SOBRE O PATENTEAMENTO DO JAMBÚ
}

No final do ano de 2018, a mídia televisa, a internet, bem como jornais escritos, noticiaram que o jambú, planta originária da região Amazônia, teria sido patenteada por empresa dos Estados Unidos da América. Segundo alguns sites de notícias, até mesmo a pesquisa dentro do país, teria sido comprometida.

Houve uma comoção na sociedade e comunidade cientifica, uma vez que o patenteamento implica em restrição ao direito de uso da planta, planta essa que é muito utilizada na culinária amazônica. Diversas foram as discussões em âmbito acadêmico a respeito do assunto. Mas teria os Estados Unidos da américa, direito a patentear uma espécie viva de outra país, somente sob o condão de "cheguei primeiro ao patenteamento?". Ou será que podemos considerar isso mais uma espécie de biopirataria?

Nesse sentido Pozzetti e Mendes destacam (2014, p. 211):

\begin{abstract}
O Brasil subestimou a cobiça estrangeira, e, em 1913, com a ausência de leis protetivas, tivemos o primeiro ataque dos biopiratas: 70 mil sementes foram contrabandeadas do Brasil e levadas para plantações na Malásia, que, cultivadas em terreno adequado e de fácil acesso, permitia a produção em larga escala e a inserção do produto no mercado consumidor, com mais facilidade e menor preço e, em pouco tempo, a borracha cultivada na Malásia substituiu a borracha "selvagem da Amazônia" no mercado mundial, com um preço mais baixo, pois a coleta e o transporte eram menos onerosos que a borracha produzida no Amazonas.
\end{abstract}

Assim sendo, podemos considerar que o jambu foi o alvo da subtração por piratas, para desenvolvimento de produtos e exploração econômica de outro país; entretanto, isso não lhe dá o direito de patentear um ser vivo que não pertence à região e ao clima, uma vez que tal planta não sobreviverá ali e mesmo que sobrevivesse, a 
origem dela é de outra região. Nesse sentido, para exemplifica, Pozzetti e Mendes (2014, p. 211) se utilizam do caso da seringueira/borracha e destacam que:

Levado esse patrimônio genético, clandestinamente, sem autorização ou qualquer paga e sem proteção legal, o Brasil e o Estado do Amazonas perderam muito, haja vista que as sementes levadas de forma irregular, fizeram nascer um concorrente potencial e desleal que acabou sucumbindo a economia do Estado do Amazonas.

Dentre as substâncias extraídas do jambu, está em destaque a chamada spilantol, muito valorizada na culinária, mas também com propriedades medicinais de grande valor, como define Cavalcanti $(2008$, p.28):

Spilanthes acmella var oleraceae ou Spilanthes oleraceae ou Acmella oleraceae, conhecida no Brasil por jambu, e uma erva típica da região norte do Brasil, onde faz parte de pratos da culinária local como o tacacá e o pato no tucupi. Conhecida também pelos nomes de agrião do Pará, agrião do Norte, agrião bravo, agrião do Brasil, botão de ouro, dentre outros, tem suas inflorescências compostas de flores amarelas e suas folhas e flores tem um sabor picante e causam leve formigamento e entorpecimento da língua.

Entretanto, para patenteá-la, é necessário que se verifique o que a legislação diz a respeito de patenteamento de um ser vivo, sem que esse the altere as qualidades ou composição.

É importante destacar que no caso da biodiversidade amazônica, o biopirata não se apropria somente da planta, ele também se apropria de conhecimentos tradicionais, aqueles em que as populações tradicionais detém, ao longo dos séculos.

Para Pozzetti, Brito e Leite (2019, p. 95) os conhecimentos tradicionais nada mais são aqueles que:

Os conhecimentos tradicionais, aqueles passados de gerações à gerações, entre os povos tradicionais (indígenas, ribeirinhos, quilombolas, ...) constitui um patrimônio invisível, que foi conquistado ao longo dos anos, com a sabedoria popular e experimentações. Os saberes sobre como utilizar um determinado animal ou vegetal, para curar males ou utilização como cosméticos, é de domínio dos povos tradicionais, da floresta, que convivem com essa fauna e flora, ao longo de centenas de anos. 
No caso do jambú, a empresa de biotecnologia, ao se aproximar da população primitiva, descobriu os benefícios que a planta oferece, conhecimentos esses adquiridos através da tradição dos povos originários que já a utilizam-na na culinária, nas infecções e outros. De posse desse conhecimento, a empresa de biotecnologia economiza em tempo e recursos financeiros "anos de pesquisa" e se apropria do conhecimento milenar sem nada dar em troca e, depois, buscam patentear a planta. Nesse sentido, Pozzetti, Brito e Leite (2019, p.96):

Durante muitos anos os conhecimentos tradicionais associados à manipulação de patrimônio genético vêm sendo utilizados por empresas de biotecnologia e pesquisadores para aprimorar o conhecimento científico e, assim, serem empregados na produção de novos produtos. Dessa forma, a utilização desses conhecimentos pelas Empresas de Biotecnologia acelera o conhecimento das propriedades e princípios ativos que plantas e animais silvestres possuem, economizando tempo e dinheiro.

Outro caso de biopirataria, que ocorreu em relação à biodiversidade da Amazônia, sobre patentes de organismo vivo, foi o caso da fruta "cupuaçu", patenteada pelos japoneses, que posteriormente foi anulada pela $\mathrm{OMC}$ - Organização Mundial do Comércio, por se tratar de um organismo vivo, sem qualquer alteração na sua modificação genética, portanto, impossível de ser patenteado. Nesse sentido Pozzetti e Mendes (2014, p. 212) esclarecem:

Tivemos, recentemente, a ação do Japão que patenteou o nome cupuaçu, planta típica da floresta amazônica. E por que o fez? Porque levaram as sementes do fruto e as analisaram em laboratório e descobriram que a semente da fruta produz um chocolate mais saboroso e mais rentável que 0 chocolate produzido a partir do cacau. Patentear o nome significa manter 0 monopólio sobre a fruta e seus derivados, contra qualquer outra tentativa, e mesmo do Brasil, de comercialização da fruta, rendendo bilhões aos cofres japoneses, enquanto o Brasil e a Amazônia novamente perdem.

E continuam Pozzetti e Mendes (2014, p. 213):

De igual forma os franceses levaram o pau rosa e o pequeno animal gambá, estudaram-nos e desenvolveram técnicas de fixar seus perfumes, o que tornou a França famosa e economicamente viável na produção de perfumes, pois os fixadores produzidos a partir desses produtos, tornaram a indústria 
de perfumes francesa altamente rentável e, ao Brasil, novamente nada se deu em troca. A França continua a faturar muito com a produção de perfumes, e desse lucro nada retorna ao Brasil.

Assim sendo, verifica-se que a ausência de legislação é alo muito perigoso para a diversidade biológica da Amazônia e para o Brasil. Ao mesmo tempo que a existência de uma legislação eficaz, é extremamente urgente e importante para consolidar os direitos brasileiros sobre a sua biodiversidade.

\section{PATENTES DE PLANTAS : É POSSÍVEL?}

O conceito de patentes é bem simples, por assim dizer, nada mais é que um título concedido pelo Estado por invenção ou modelo de utilidade a pessoas físicas ou jurídicas, que, a partir da concessão da patente, detém a propriedade daquela invenção ou modelo de utilidade temporariamente, impedindo que seja replicado sem autorização ou devido pagamento. O Instituto Nacional de Propriedade Industrial INPI, que é o responsável por essa titulação, destaca na lei oㅡ 9.279/1996: "Art. 8o. É patenteável a invenção que atenda aos requisitos de novidade, atividade inventiva e aplicação industrial. (g.n)."

Nesse sentido, Pozzetti, Brito e Leite (2019, p.98), esclarecem sobre o conceito de patente:

O conjunto de categorias denominado propriedade intelectual compreende referencialmente os bens imateriais da propriedade do empresário, sendo estes: patentes, marcas ou nomes empresariais. O direito patentetário, ligado à propriedade industrial, surgiu como um mecanismo de proteção da imaterialidade da propriedade intelectual.

E continuam Pozzetti, Brito e Leite (2019, p. 98):

Originalmente, até século XIX, período da Revolução Industrial, não existia uma legislação apropriada que regulamentassem as patentes, sendo aplicada, muitas vezes, a legislação de um país em outro. Enfim, em 1883, um grande passo foi dado, resultado da progressão da internacionalização 
do comércio intelectual, que foi a edição da Convenção da União de Paris (CUP).

É de se destacar que o direito patentário, no Brasil, ganhou status de direito fundamental, com o advento da Constituição federal de 11988, que em seu artigo 5을 estabeleceu:

\begin{abstract}
Art. 5ำ Todos são iguais perante a lei, sem distinção de qualquer natureza, garantindo-se aos brasileiros e aos estrangeiros residentes no País a inviolabilidade do direito à vida, à liberdade, à igualdade, à segurança e à propriedade, nos termos seguintes: [...] omissis XXIX - a lei assegurará aos autores de inventos industriais privilégio temporário para sua utilização, bem como proteção às criações industriais, à propriedade das marcas, aos nomes de empresas e a outros signos distintivos, tendo em vista o interesse social e o desenvolvimento tecnológico e econômico do País; (gns).
\end{abstract}

Desta forma, podemos entender que no Brasil só pode ser patenteado invenções ou produtos que sejam produzidos pelo homem, que possa ser produzido, aplicado industrialmente; deve ser uma novidade, ou seja, não existir registros iguais.

É importante destacar que a lei de no 9.279/96, ainda estabelece um rol de situações que não podem ser submetidos às patentes:

Art. 18. Não são patenteáveis: I- o que for contrário à moral, aos bons costumes e à segurança, à ordem e à saúde públicas; II- as substâncias, matérias, misturas, elementos ou produtos de qualquer espécie, bem como a modificação de suas propriedades físico-químicas e os respectivos processos de obtenção ou modificação, quando resultantes de transformação do núcleo atômico; e III - o todo ou parte dos seres vivos, exceto os microorganismos transgênicos que atendam aos três requisitos de patenteabilidade - novidade, atividade inventiva e aplicação industrial previstos no art. 8 e que não sejam mera descoberta. Parágrafo único. Para os fins desta Lei, microorganismos transgênicos são organismos, exceto o todo ou parte de plantas ou de animais, que expressem, mediante intervenção humana direta em sua composição genética, uma característica normalmente não alcançável pela espécie em condições naturais. (g.n)

Importante destacar que a lei brasileira, de Patentes, estabelece que não é possível patentear dentro do território nacional, seres vivos, no todo ou em parte, nem mesmo substâncias, misturas ou processos de obtenção.

Nesse sentido, Pozzetti e Mendes (2014, p. 220) destacam: 
Dessa forma, percebe-se que os bens ambientais primários possuem um valor inestimável à indústria de transformação; logo, possuem valor econômico, e o uso desses recursos, ou a utilização desses pela indústria de transformação, deve ser remunerado em benefício da coletividade, que contribui para que haja a oferta desse bem ambiental.

Assim, dentro do território brasileiro não é possível que o Estado conceda a patente do Jambú. Nesse sentido, assevera Diniz (2001, p.445):

Os organismos vivos não são invenções humana, mas produtos da natureza, e a biotecnologia somente copia e efetua a recombinação das "peças" soltas desse instrumento que é a vida. (gn).

Para aclarar o que seria "organismos vivos" a lei no 11.105/2005, Lei de biossegurança destaca que: "Art. 3ํ․ (...) omissis I - organismo: toda entidade biológica capaz de reproduzir ou transferir material genético, inclusive vírus e outras classes que venham a ser conhecidas (...)".

Assim sendo é importante destacar a explicação de Pozzetti, Brito e Leite (2019, p.100):

\begin{abstract}
Dessa maneira, a Lei das Patentes brasileira (Lei o 9.279/96), que regulamenta os acordos internacionais, os quais o Brasil é parte, bem como o disposto no texto constitucional, visa proteger a propriedade intelectual através da concessão de patentes de invenção e de modelo de utilidade, registro de marcas e desenhos industriais, além de regulação de outros direitos e obrigações.
\end{abstract}

Juridicamente não é possível ter a propriedade de um organismo vivo, no Brasil, pois o legislador partiu do entendimento de que, para ser patenteável, deve ser produto de criação humana e novidade, produzida com intuito comercial.

Patente é, portanto, uma ferramenta de proteção, que permite que o inventor explore economicamente durante um tempo que varia de 10 ou 15 anos (art. 40 da lei de patentes): "Art. 40. A Patente de invenção vigorará pelo prazo de 20 (vinte) anos e a de modelo de utilidade pelo prazo 15 (quinze) anos contados da data de depósito".

Já no território americano, há leis onde se permite que sejam patenteados fórmulas e organismos vivos. Para se adquirir uma patente vigente em vários lugares 
do mundo, é preciso requerê-las no território ao qual se deseja e, ainda, de acordo com as normas especificas do lugar. Ou seja, não existe atualmente, um meio específico de titulação que valha em âmbito mundial, contudo, há um tratado multilateral chamado de PCT, ao qual se permite requerer a patente, simultaneamente, em 152 países e é administrada pela Organização Mundial de Propriedade Intelectual - WIPO. Porém, devem ser seguidos padrões exigidos e pagar as taxas de acordo com cada país que deseja obter o título, conforme informações do próprio site.

Neste sentido destacam Pozzetti, Brito e Leite (2019, p.99):

A OMC é uma organização multilateral, internacional e independente, para construção, defesa e desenvolvimento do sistema mundial do comércio, possuindo como um de seus principais instrumentos o Acordo sobre Aspectos dos Direitos de Propriedade Intelectual relacionados ao Comércio (ADPIC TRIPS), pelo qual surgiu o sistema de patentes que vigora atualmente nos países consignatários do acordo. No Brasil, o TRIPS foi incorporado ao direito interno por intermédio do Decreto no 1.355, de 30 de dezembro de 1994, mais tarde fundamentando a Lei oㅜ 9.279, de 14 de maio de 1996, que regula direitos e obrigações relativos à propriedade industrial.

No que concerne ao âmbito nacional, a vulnerabilidade desta lei no país, causa efeitos negativos ao Estado e à população, como por exemplo, a perda econômica na exploração de conhecimentos e produtos nativos que em escala de produção para o comércio, favoreceria o país e a sociedade, no caso desta ser explorada exclusivamente por empresas ou produtores nacionais. Nesse sentido, esclarece Santos (2014, p.305):

Uma das vertentes da sustentabilidade diz respeito ao desenvolvimento de tecnologias ambientalmente amigáveis, ou seja, tecnologias que se preocupam com os impactos decorrentes da atividade na qual serão aplicadas. Ocorre que tais tecnologias, fruto do capital intelectual, merecem proteção jurídica suficiente, de modo que o autor possa ter um retorno, tendo em vista o que fora despendido até se chegar ao resultado final. 


\section{CONCLUSÃO}

A problemática que movimentou essa pesquisa foi a de se verificar-se de que forma o Brasil pode evitar que povos alienígenas patenteiem plantas da biodiversidade amazônica. Os objetivos da pesquisa foram atingidos à medida em que se analisou a Lei de patentes e buscou-se subsídios na doutrina para se verificar se é possível patentear um ser vivo, no Brasil, por povos alienígenas.

Verificou-se que os Decretos e Portarias regulamentadoras que o Brasil possui não são suficientes para amparar e proteger o patrimônio genético, de usurpadores ou biopiratas. A sociedade brasileira perde muito, não só economicamente, mas também culturalmente, pois os recursos naturais acabam por ser explorados por empresas e instituições estrangeiras, sem que haja rigor e controle. Além disso, verificou-se, também que os povos tradicionais da Amazônia brasileira são enganados pelas empresas de biotecnologia que também roubam-Ihes os conhecimentos adquiridos em séculos de tradições e nada pagam por isso.

Além disso, a pesquisa cientifica interna também sofre com os obstáculos encontrados, gerando uma "menos valia" à cultura e tradições amazônicas. O Brasil possui um grande potencial em Patrimônio Genético, que precisa ser protegido. Isso significa que as leis brasileiras, que hoje existem, para proteção do meio ambiente e patrimônio genético, não são eficazes e demonstram a vulnerabilidade a que o pais fica exposto.

As pesquisas realizadas com o jambú em terras alienígenas, demonstram a inércia do governo brasileiro em investir em pesquisas e, em assegurar direitos nacionais, sobre a flora brasileira.

Conclui-se que, no Brasil o Jambú ou qualquer outro organismo vivo, no todo ou em parte, não poderá ser patenteado e que, aquilo que não são criações humanas, não estão passíveis de patente. Assim sendo, o patenteamento do Jambú, por quem quer que seja, seja no Brasil ou fora dele, se constitui em ato ilícito e o Brasil, caso alguém tente fazê-lo, desconstituirá essa patente na Organização Mundial do comércio, como já o fez no caso do cupuaçu, patenteado pelo Japão. 


\section{REFERÊNCIAS}

BRASIL, Constituição da República Federativa do. Congresso Nacional, Brasília, 1.988.

. Lei de Propriedade Industrial. Lei no 9.279 de 14 de maio de 1996. Congresso nacional, Brasília, 1996.

. Lei no 11105 de 24 de março de 2005. Congresso Nacional, Brasília, 2005.

DINIZ, Maria Helena. O estado atual do biodireito. São Paulo: Saraiva, 2001. p. 445.

CAVALCANTI, V. M. S. Extração de espilantol de Spilanthes acmella var oleraceae com dióxido de carbono supercrítico. Tese (Doutorado em Química) Universidade Estadual de Campinas, 2008. p. 28.

INPI - Instituto Nacional de Propriedade Intelectual. Manual depósito patente, 29/05/2019. Disponível em: http://www.inpi.gov.br/menu-servicos/patente/guiabasico-de-patentes. Consultado em 21 jan. 2020.

POZZETTI, Valmir César; MENDES, Máryka Lucy da Silva. Biopirataria na Amazônia e a ausência de proteção jurídica Revista Direito Ambiental e Sociedade, v. 4, n. 1, 2014 (p. 209-234).

; BRITO, Ana Carolina Lucena; LEITE, André Luís Fregapani. Conhecimentos Tradicionais e o Direito Empresarial às Patentes. Revista Percurso, vol.04, $n^{\circ} .31$, Curitiba, 2019. pp. 93 - 106 - DOI: 10.6084/m9.figshare.11348861 disponível in: http://revista.unicuritiba.edu.br/index.php/percurso/article/view/3702/371372067, consultado em 02.fev.2020.

SANTOS, Nivaldo dos; OLIVEIRA, Diego Guimarães de. A patenteabilidade de tecnologias verdes como instrumento de desenvolvimento sustentável, Revista Juridica Unicuritiba. v.4,n. 37, 2014, p. 305. Disponível em: http://revista.unicuritiba.edu.br/index.php/RevJur/article/viewFile/1051/738, consultada em 25 mai. 2019.

WIPO - site: PCT - The International Patent System. Disponível em: https://www.wipo.int/pct/en/, consultado em 29 mai 2019. 